\title{
LA CAPILLA DE SAN ANTONIO DE LOS PORTUGUESES DE SEVILLA
}

\author{
POR María Jóse del Castillo Utrilla
}

\begin{abstract}
Presentamos aquí las primeras noticias acerca de la Hermandad de los Portugueses en el Convento Casa Grande de San Francisco de Sevilla. El Libro de Reglas de esta Hermandad, bellamente ilustrado, se conserva en orro convento de la ciudad. Nosotros presentamos ahora por vez primera este Libro de Reglas y hacemos un estudio tanto estilístico como iconográfico. Asimismo se da una panorámica acerca de la trayectoria de la Hermandad.
\end{abstract}

We present here the first news about a Portugues Foundation in the Main Convent of Saint Francisco at Seville. The Regulations of this Foundation remain still in the archive of the other convent, illustrated whith beautiful pictures. Now we present for the first time this Regulations' book, an also we make a study of the pictures and its iconography. Some glances are make about the Foundation developing.

Las investigaciones histórico-artísticas, son, como todas, dificultosas, y requieren una buena dosis de paciencia. Pero cuando el objeto que llama nuestra atención no existe, se ha desvanecido y solamente podemos rastrearlo a través de unos cuantos documentos dispersos, y en ocasiones contradictorios, la cuestión se nos presenta bastante ardua.

Si sobre ello tenemos la osadía de pretender no solo reconstruir su historia, sino además intentar poner de manifiesto de manera gráfica lo que debió ser, la labor puede llegar a ser apasionante, pero también desagradecida. Al final, aquello se puede convertir en un puzle endemoniado.

Eso, un puzle endemoniado ha supuesto el intento de "rehacer" la Capilla de San Antonio de los Portugueses de Sevilla. No sé si el resultado será óptimo, pero al menos considero que puede dar pie a elucubraciones y que incluso puede sentar las bases para que cualquier investigador más autorizado que yo diga: $\mathrm{Te}$ equivocaste de medio a medio. Eso nunca fue así.

La Capilla de los Portugueses, ya por su propia ubicación, es imposible de perimetrar, a pesar de los datos relativamente concretos que tenemos y que hemos estudiado documentalmente. 
Se situaba, eso sí, en el Atrio o Compás del extinto y desaparecido Convento Casa Grande de San Francisco de Sevilla y en 1842, desapareció de la faz de la tierra, al mismo tiempo que el monasterio franciscano.

La misma suerte que corrió el conjunto religioso en el que había tenido acogida la fundación, tuvo la de los Portugueses. Podríamos decir que se volatilizó.

Recurriendo a los datos históricos que constan en el Archivo Franciscano de la Provincia Bética, sabemos que la colonia lusa asentada en Sevilla, demandó al P. Provincial de los Frailes Menores un lugar para fundar una Capilla en la que celebrar sus cultos específicos.

Esta solicitud tuvo lugar en 1594, ante Fray Pedro de Gallarza, máxima autoridad de la Provincia Franciscana.

Con anterioridad ya habían obtenido este privilegio de fundación dos asociaciones más. La de Animas o de San Onofre, que todavía pervive, y que fue fundada en 1520, y la de la Concepción, desaparecida con la extinción del Convento Casa Grande de San Francisco, y que había sido fundada en 1536 aproximadamente.

La Cofradía y Hermandad de los Portugueses, por tanto, fue la tercera que se estableció en el Atrio del Convento Franciscano. (Hemos de tener en cuenta que para nada se trata en este trabajo de el resto de Hermandades y Cofradías que tenían un sede en el Templo Conventual a los establecimientos que existieron en el Atrio).

Como decíamos anteriormente, la Hermandad de los Portugueses, consigue establecerse en el Atrio de San Francisco en el año 1604, en el que era Provincial de la casi recién fundada Provincia Bética, el Padre Fray Juan de Benjumea. (Debemos observar que la distribución territorial de la O.F.M., no se establece de una manera efectiva hasta la reforma de la Orden en 1587 , bajo el Generalato de Fray Francisco Gonzaga).

El Padre Juan de Benjumea accedió a conceder a esta "Nación Portuguesa", unos terrenos dentro del perímetro que pertenecía al convento franciscano, no sin puntualizar muy severamente una serie de condiciones que los nuevos "inquilinos" tendrían que cumplir. Condiciones que es claro, beneficiaba a la comunidad de los Frailes Menores.

Por otra parte, los Portugueses establecidos en Sevilla, debían gozar también de rentas bastante aseadas, cono se desprende de los gastos que pudieron hacer en la construcción y aseo de su Capilla, y en el mantenimiento de la misma, así como en el beneficio de las obras de la Comunidad franciscana.

La verdad es que después de una serie de controversias, en el año de 1604, los Franciscanos y los Portugueses, llegaron a un acuerdo y la Hermandad quedó establecida en los terrenos del Convento.

La parte que se le concedió a la Hermandad de los Portugueses, fue la más amplia de la zona del Atrio franciscano.

Se fundó originalmente con el nombre de Las Cinco Llagas, aunque muy pronto, se cambió este nombre por el de San Antonio de los Portugueses, denominación por la que es conocida y está inscrita en la documentación que hemos consultado. 
Como decíamos, los terrenos que se le otorgaron a la Hermandad de San Antonio de los Portugueses, fueron muy generosos, aunque para su ocupación y la edificación de sus casas, tuvieron que ajustarse a unas ciertas normas, impuestas por los frailes.

Estas normas estaban encaminadas a no entorpecer la vida de la Comunidad, no a desfigurar el conjunto conventual, en el sentido de salubridad y convivencia, que no creo yo que en ningún momento esto atañera al aspecto estético.

Así, tomando notas de diferentes documentos (véase su relación al final de este estudio), nos encontramos con las más antiguas al respecto, que son precisamente las que nos proporciona el Padre Benjumea.

El propio Padre Benjumea, en las memorias del Convento de San Francisco, más tarde refrendadas por el Padre Ortega en sus famosos "Papeles", expresa que los portugueses "ocuparon el sitio de las caballerizas bajas que salen al compás que lindan por una parte con la puerta de las bestias (pajerias bajas) y por otra con la Capilla de las Animas (San Onofre) y demás de las dichas caballerizas se podrán extender con la obra dentro de la guerta del convento 42 pies de lo que dice el sitio de la Alberca, con la condición que la obra que edificaren no quite luz a ninguna ventana alta ni baja del dormitorio".

Otras puntualizaciones igualmente interesante acerca de la extensión y localización de los terrenos cedidos, nos las proporciona una escritura fechada en 1594, firmada por los escribanos Hernando de Lorenzo y Francisco Mazuelos, el día 2 de septiembre del citado año, en la que se especifica que "... se le han señalado para ello (la fundación) la frontera del Compás del dicho Monasterio desde la Capilla de Animas hasta la puerta del servicio de dicho Monasterio y de ancho lo que va desde la puerta de dicho servicio hasta la esquina de los dormitorios de la traviesa hasta un pajar con la pared de la Alberca".

Otro documento acerca del mismo tema de los terrenos que la Capilla debía ocupar, está fechado el 3 de agosto de 1604, y firmado por los escribanos Juan de Rojas y Juan de Carranza.

En esta escritura se insiste en remarcar el espacio cedido a la fundación de los portugueses y en el se expresa que se les concede "el sitio que hay desde el fin y remate de la casa que sirve de pajar de este medio, siguiendo la línea recta hasta el fin y remate de la obra que hace esta nación portuguesa por el ancho, de modo que este sitio tiene siete varas mas o menos por las partes de dicho pajar y tres varas por la parte de la Alberca".

Estos dos últimos documentos vienen a ser la base de lo que mas tarde refleja en sus escritos el Padre Benjumea en 1648, y que en el siglo XIX recopila el Padre Ortega, en sus famosos "Papeles".

Sin duda, estas descripciones, plantean algunos problemas de precisión respecto a localizar de una manera fiel cuál fue el terreno que en la actual Plaza Nueva y sus aledaños ocupó la Capilla de los Portugueses. 
Recurriendo a una descripción de este ámbito, que recientemente (1897), proporciona el cronista franciscano Fray Atanasio López de Vicuña, los perímetros y situación de la Capilla de los Portugueses no se acopla con rigor a lo que se desprende de los documentos que anteriormente resumimos.

En la totalidad de los gastos de su construcción se invirtieron, sin contar con las cesiones monetarias dadas a los franciscanos, a cambio de las cesiones de terrenos, 30.000 ducados.

Independientemente de estos gastos, estaban las prevendas dadas a la comunidad, bastante bien estipuladas por ambas partes.

A cuenta de este contrato, y de los bienes que la comunidad franciscana obtuvo de su transacción con los portugueses, se consiguió reformar el Claustro Grande del Convento, y enlosarlo con mármoles de Génova.

También la dádiva de los Portugueses a cambio del terreno cedido por la Comunidad Franciscana, permitió renovar el Claustro Chico, que antecedía a la entrada axial de la Iglesia Conventual Franciscana.

Ambos claustros, fueron reenlosados y decorados con pinturas sus muros, a costa de la Hermandad de los Portugueses.

Estos datos que nos proporcionan, entre otros autores, Fray Atanasio, pueden acogerse sin reservas, ya que él redacta su obra en 1897, después de la restauración de la Comunidad Franciscana en San Buenaventura y cuando el conjunto de San Francisco había desaparecido. Si conoció la obra antes de su destrucción, lo que supone unos 55 años de antelación a la fecha indicada, no lo sabemos.

Lo que sí es evidente, si observamos atentamente la descripción de la Capilla de los Portugueses y estudiamos los distintos documentos podemos intuir que fue una de las más ricas y amplias de cuantas integraron el conjunto monástico.

La Capilla se nos describe así. "La Iglesia era de tres naves, con columnas de mármol duplicadas que sustentaban los arcos y en las naves laterales tenían sus altares y sus capillas con retablos y esculturas y toda ella estaba adornada con cortaduras de yesería.

También de yesería preciosamente dorada era el techo de la Capilla. en la altura de los muros se seguia la misma división que en la parte baja.

Una reja de caoba recorre en el tercio superior toda la Capilla y hacía de tribuna y de coro".

Esta reja era obra de Juan Cano y era de tabla calada como las de la Capilla Mayor. Su ejecución fue tardía. Se contrató por 10.500 Reales de vellón en 1754, siglo y medio después de la iniciación de las obras del recinto de la Hermandad.

Las dilaciones, reformas y otras innovaciones en la ejecución de cualquier obra, son moneda común en todos los tiempos, por eso, el intentar dar una idea precisa de "como es esto", aunque sea con pocos años de diferencia a su primer contacto con "esto", tiene por delante un camino muy difícil, podría decir que prácticamente insalvable. 
Dentro del recinto eclesial, siguiendo la descripción que se hace del mismo, consta que el Presbiterio estaba separado de la nave por una reja de hierro dorada y del mismo material y traza era el púlpito.

Desde el exterior de la Capilla, hacia la nave, había un cancel de madera que resguardaba la entrada desde la calle al interior del templo.

La tipología que se deduce de los distintos relatos y apuntes sobre la Capilla de San Antonio de los Portugueses responde a un esquema muy simple. Era de tres naves, con tribuna sobre las laterales, bóveda de cañón con lunetos, crucero y ábside, posiblemente de testero plano. Los soportes, de columnas pareadas. La decoración, de yesería.

Respecto a la ornamentación de los elementos que formaban parte integrante del edificio de la iglesia, como consideramos las verjas, canceles, etc., hay pocos datos de ellos, quizás el más preciso es el que corresponde al cancel que separaba la calle de la iglesia, este elemento, tallado en madera, "se hizo según la traza de Juan Cano y era chaflanado a dos hacer y moldado con los juguetes y armas portuguesas".

Es presumible que el resto de los elementos de esta clase, maderas y hierros en particular, siguiesen un esquema de barroquismo bastante asentado y que los motivos heráldicos fuesen frecuentes como elementos de decoración, y que debiéndose los trabajos de maderas a Juan Cano, tanto en lo que se refiere al recién nombrado cancel, como al resto de los elementos de este tipo, (coro, tribunas y rejas), en todos ellos dejara la impronta de su estilo y repitiera los elementos que, aunque sucintamente, se nos describen en referencia al cancel ya tan citado.

No debieron tampoco faltar alusiones o símbolos referentes a la Orden de San Francisco, aunque no hemos encontrado ninguna puntualización sobre ello. Pero dado el lugar en que se ubicó la fundación, el que su Patrón fuese San Antonio, uno de los Santos más conocidos de la Orden y el que la primera denominación de la Cofradía fuera la de Las Cinco Llagas, emblema máximo de la heráldica de la O.F.M., es de pura lógica creer que las alusiones formales al franciscanismo estuvieran muy presentes.

En el interior del templo la pieza que requiere más interés, es sin duda el Retablo del Altar Mayor.

La documentación que hay acerca de él, es abundante, pero como en tantas otras ocasiones, no las descripciones son muy precisas, ni mucho menos se han encontrado trazas ni elementos que nos lleven a ninguna concreción acerca del aspecto del mismo.

Veamos lo que se nos dice acerca del mismo, sobre todo en lo que atañe a su proceso de realización, que como veremos es largo y complicado.

El Duque de Veragua contrató con Felipe de Rivas un retablo para la Capilla de los Portugueses, en el año 1642, pero las cuestiones económicas fundamentalmente, hicieron que la ejecución definitiva de la obra, se fuera retrasando de 
manera alarmante y que los síndicos de la Cofradía, así como los miembros en general de la misma, no cesaran en sus reclamaciones, tanto ante el Duque como ante el artista.

Este contrato primitivo del 8 de octubre de 1642, permaneció en vigor hasta 1648, año en el que debido al impago por parte del Duque de Veragua al artista, se reúne la Junta de la Cofradía de los Portugueses, concretamente el 5 de julio, y en acuerdo general determinan que cada diputado de la Cofradía aporte 400 Reales para sufragar los gastos que Rivas estaba haciendo en las obras de la Capilla.

Es en este año de 1648 cuando Felipe de Rivas traslada el encargo del Retablo Mayor de los Portugueses, a su hermano Dionisio de Rivas.

No obstante, el pleito no concluye con este traspaso, porque las demandas continúan, y es necesario recurrir a una nueva aportación monetaria por parte de los miembros de la Cofradía en 1652, para el pago del encargo. En esta ocasión la cifra conseguida es de 5.725 Reales de Vellón, cantidad que permitió proseguir la obra, aunque para concluirla, aún tiene la Cofradía que aportar una nueva cantidad en el año 1697, para que se haga el ático del cuerpo central.

Parece ser que con esta entrega económica, se termina el encargo, y que el mismo año ya está ensamblado y colocado en la cabecera del templo.

No tenemos constancia de la disposición iconográfica del Retablo que los Rivas realizaron para los portugueses, pero siguiendo modelos de la época lo más posible es que la hornacina central estuviese ocupada por la imagen del Santo titular, acompañado en las calles laterales por figuras de santos de la Orden Franciscana, entre las que no debía faltar la de Santa Isabel de Portugal, Terciaria de dicha Orden, tal vez también apareciera Santa Clara, haciendo pareja con Santa Isabel. En el ático del retablo, casi inevitable sería la figura de la Inmaculada Concepción y como emblemas a la vez que elementos de decoración, el escudo de las Cinco Llagas (no olvidemos que esta fue la primera denominación de la fundación lusa), pareado con las armas de Portugal.

De ningún documento hemos podido sacar datos acerca de esta composición, solamente en lo que atañe a San Antonio, Patrón definitivo de la Cofradía, tenemos noticias relativamente precisas.

La imagen de San Antonio estaba terminada, en los talleres de los Rivas en 1658 , aunque a la misma le faltaba el estofado y el policromado. Para que esta terminación pudiera hacersele, el mismo año la corporación consiguió la cantidad de dinero suficiente para pagar a Francisco de Fonseca, maestro de estofado y que terminara la decoración de la escultura.

No se especifica nada más acerca de ella, y en la documentación tardía, referente al reparto de los objetos de esta Capilla, a partir de su destrucción, solamente encontramos el dato de que le fue entregada al Cónsul de Portugal, y que estuvo depositada en la Parroquia de San Juan de la Palma. 
Debido a los múltiples traslados de las imágenes que pertenecieron a las fundaciones situadas en el convento franciscano, la localización de este San Antonio, como la de tantas otras piezas, es poco menos que imposible, aunque es probable que dadas sus características, se trate de una imagen que se encuentra en la Iglesia de San Ildefonso, a la que fueron a parar varias obras procedentes del extinguido Convento. Pero esto no es más que una suposición gratuita, sin mayor solidez.

Dejando ya lo referente al Retablo, continuemos con el adorno del resto de la Capilla, que también parece que fue haciéndose sin demasiadas prisas, según las cuentas que del mismo encontramos, como finiquito de los pagos que por ellas se hicieron el 28 de julio de 1726, y que montó un total de 31.000 Reales.

Lo interesante de este documento es que nos proporciona datos muy claros no solo acerca del tipo de decoración que el templo debió de tener, sino también la conformación del mismo, determinándose a través de la fría contabilidad, que era un edificio dividido en tres tramos, con sotocoro.

Los datos son los siguientes:

En el primer cuerpo, entrando el estofado del techo . . . . .

8.346 Rls.

En el segundo cuerpo, entrando el estofado . . . . . . . .

$6.921 \mathrm{Rls}$.

En el tercero y último de abajo $\ldots \ldots \ldots \ldots \ldots \ldots$

13.708 Rls.

Pintura de las pilastras y tarjetas $\ldots \ldots \ldots \ldots \ldots$

825 Rls.

Al final de la obra dicha se le dió al Maestro llamado

Domingo Martínez .................

1.200 Rls.

Total

31.000 Rls.

Es evidente que el responsable de la ornamentación de la iglesia, fue Domingo Martínez, quien a su vez realizó una serie completa de la vida de San Francisco, para adornar el Claustro Grande del Convento. Casa Grande de San Francisco.

En esta etapa la actividad de Domingo Martínez dentro del ámbito franciscano, debió.ser muy intensa, porque existen varias referencias a contratos y obras suyas para distintos conventos de la Orden.

Una vez destruido el Convento Franciscano, como antes decíamos, muchas de las Capillas de Naciones y de Hermandades, pasaron sus propiedades a diferentes casas religiosas o a particulares.

En el caso que nos ocupa, de los Portugueses, sabemos que al Cónsul de Portugal se le entregó una Concepción, una Piedad y un San Antonio.

Su destino final nos cuesta suponerlo, aunque dentro de la hipótesis, hemos dado con un dato clarificador, aunque no definitivo ni mucho menos.

En el convento de los Padres Filipenses de Sevilla, está el libro de Constitución de la Hermandad de San Antonio de los Portugueses. Esta obra nos 
remite a los orígenes de la Hermandad, e incluso nos hace dudar acerca de la ubicación de su propia capilla en el perímetro del Convento Franciscano.

En este libro reglar se dice que dicha Hermandad, construyó su capilla junto a la de la Vera Cruz. Imposible de todo punto, porque esto contradice a toda la documentación que existe y ya hemos reseñado, en los Archivos de la O.F.M.

Queda así abierta la polémica, puede ser que en un futuro se soluciones.

Pero volvamos al libro. Está hecho en cuarta, de pergamino duro, consta de 51 folios, mas cinco de iluminaciones.

Dos folios de respeto en el comienzo y otros dos al final.

Las miniaturas que lo ilustran representan consecutivamente, la Asunción de María; La Inmaculada Concepción, rodeada de símbolos lauretianos (fig.1-2), y que en su iconografía mantiene unas normas totalmente adecuadas a la Inmaculada apocalíptica.

Un San Antonio (fig.3) que se acopla a las representaciones más tradicionales, sin que varie en absoluto la imagen más conocida del Santo.

Luego, viene un San Francisco (fig.4), en la escena de la Estigma, con una escala celestial a su derecha, elemento poco frecuente en esta iconografía, y el inevitable y simpático hermano León.

Por fin, nos encontramos con el Crucificado, que se eleva sobre una hipotética Jerusalén (fig.5). Es una representación a lo barroco sin mayores aportaciones a la estética del momento.

Un estudio completo, codicología pura, sobre esta obra, sería interesante, pero en un estudio general, acerca de la Hermandad de los Portugueses, no nos cabe.

En términos generales, la obra está muy bien cuidada en su factura. La encuadernación en terciopelo rojo, está guarnecida con adornos metálicos y ostenta un escudo, en cuyo campo aparecen tres azucenas (fig.6), haciendo referencia, sin duda, al símbolo de virginidad que San Antonio ostenta en todas sus representaciones.

Según las dichas Reglas de la Hermandad, esta se constituye el 9 de mayo de 1563, bajo el patrocinio de San Antonio, a cargo de los Portugueses, "En el día de la Ascensión de Nuestro Señor".

Da el "Placet" el Vicario General de la Archidiócesis de Sevilla, D. Luis Venegas de Figueroa. No obstante, este Libro de Reglas no se ejecuta hasta 1633 y es Jacinto de Roger quien lo firma.

Casi un siglo ha pasado entre la constitución de la Hermandad y la formulación definitiva de la institución.

La obra se inicia con varios capítulos evangélicos, el primero de San Juan, uno de San Lucas y dos de San Mateo, que en una línea de continuidad van desde "En principio era el Verbo", hasta el mandato de predicación, pasando por la Anunciación y el Nacimiento de Cristo.

Luego, ya en el folio 3 vuelto, comienzan las Constituciones, y a partir del fl. 51 vuelto, las aprobaciones al uso. 
Como decía en un principio, este libro de Reglas es el único testimonio fiel de aquella Hermandad, de aquí, el valor que le damos, porque el resto de las obras que le pertenecieron, son prácticamente imposible de localizar, como se desprende de los Inventarios de la documentación de "Conventos extinguidos" del Palacio Arzobispal de Sevilla.

Aceptemos todos que estos apuntes sobre la Hermandad de San Antonio de los Portugueses no son sino eso, apuntes, que pueden abrir camino a investigaciones más profundas.

Por consiguiente, obvio las notas que corresponderían a este trabajo, y prefiero incluir al final del mismo una relación de documentos y bibliografía, que pueden facilitar a quien esté interesado en el tema, un estudio más detallado.

\section{FUENTES DOCUMENTALES}

ARCHIVO DE LA PROVINCIA BÉTICA (A.P.B.) O.F.M.- Sevilla (en San Antonio de Padua).

Legajos.- 33/40/42/43/44/47.

ARCHIVO PALACIO ARZOBISPAL.- Sevilla.

Sección Hermandades. Caja $\mathbf{n}^{\circ} 78$.

Padre Ortega- Carpeta V- (A.P.B.)

López de Vicuña, Fr. Atanasio. Relación del Convento Casa Grande de San Francisco (A.P.B.).

\section{BIBLIOGRAFÍA}

VELÁZQUEZ SÁNCHEZ, José.- Anales de Sevilla. Sevilla, 1872.

ARANA DE VALFLORA.- "Compendio histórico descriptivo de la mui noble y mui leal ciudad de Sevilla". Sevilla, 1766.

GONZÁLEZ DE LEÓN.- Noticia Artística de todos los edificios públicos de esta muy notable ciudad de Sevilla. Sevilla, 1844.

RUBIO, Germán.- La Custodia Bética. Sevilla, 1948.

DABRIO, Teresa.- "Los Rivas...". Córdoba, 1985.

DEL CASTILlo UTRILlA, Ma José.- "El Convento de San Francisco, Casa Grande de Sevilla". Sevilla, 1988.

\section{AGRADECIMIENTO:}

A la comunidad de Padres Filipinses y en especial al Padre Rafael Muñoz 


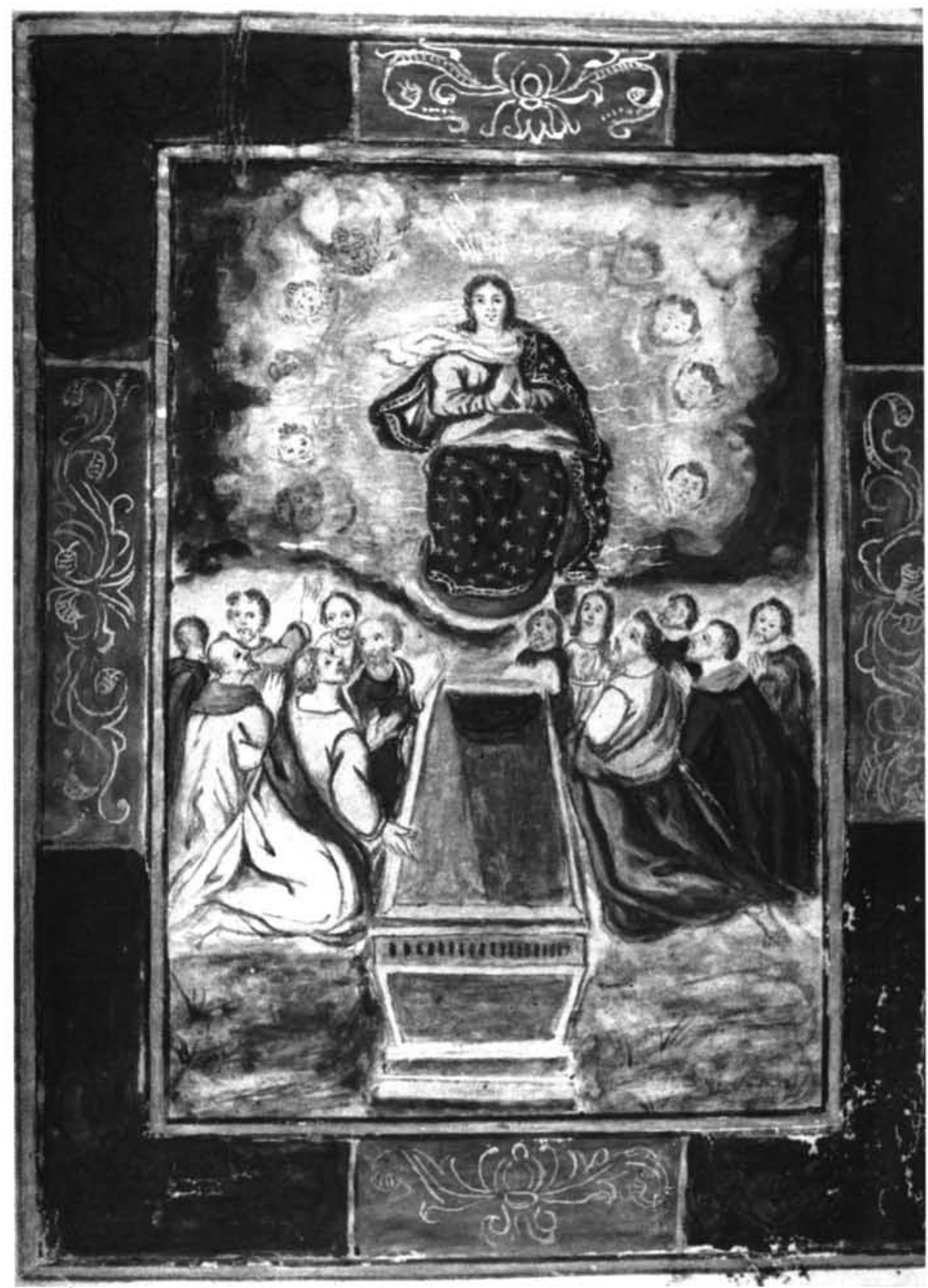

Fig. 1: Libro de Reglas: Hermandad de los Portugueses: Asunción de Ntra. Señora. S. XVII 


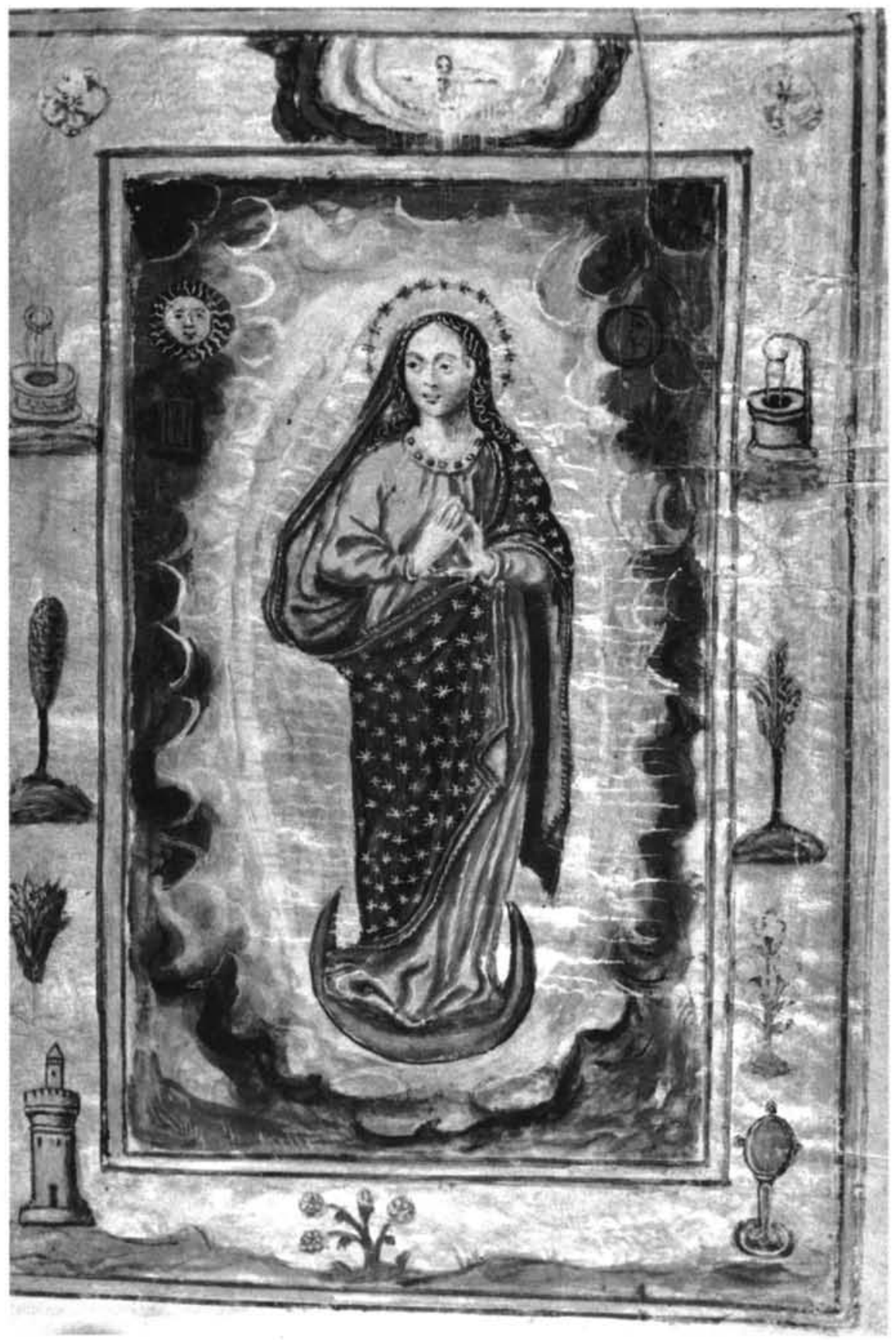

Fig. 2: Libro de Reglas: Hermandad de los Portugueses: Inmaculada Concepción con símbolos lauretanos. S.XVII. 


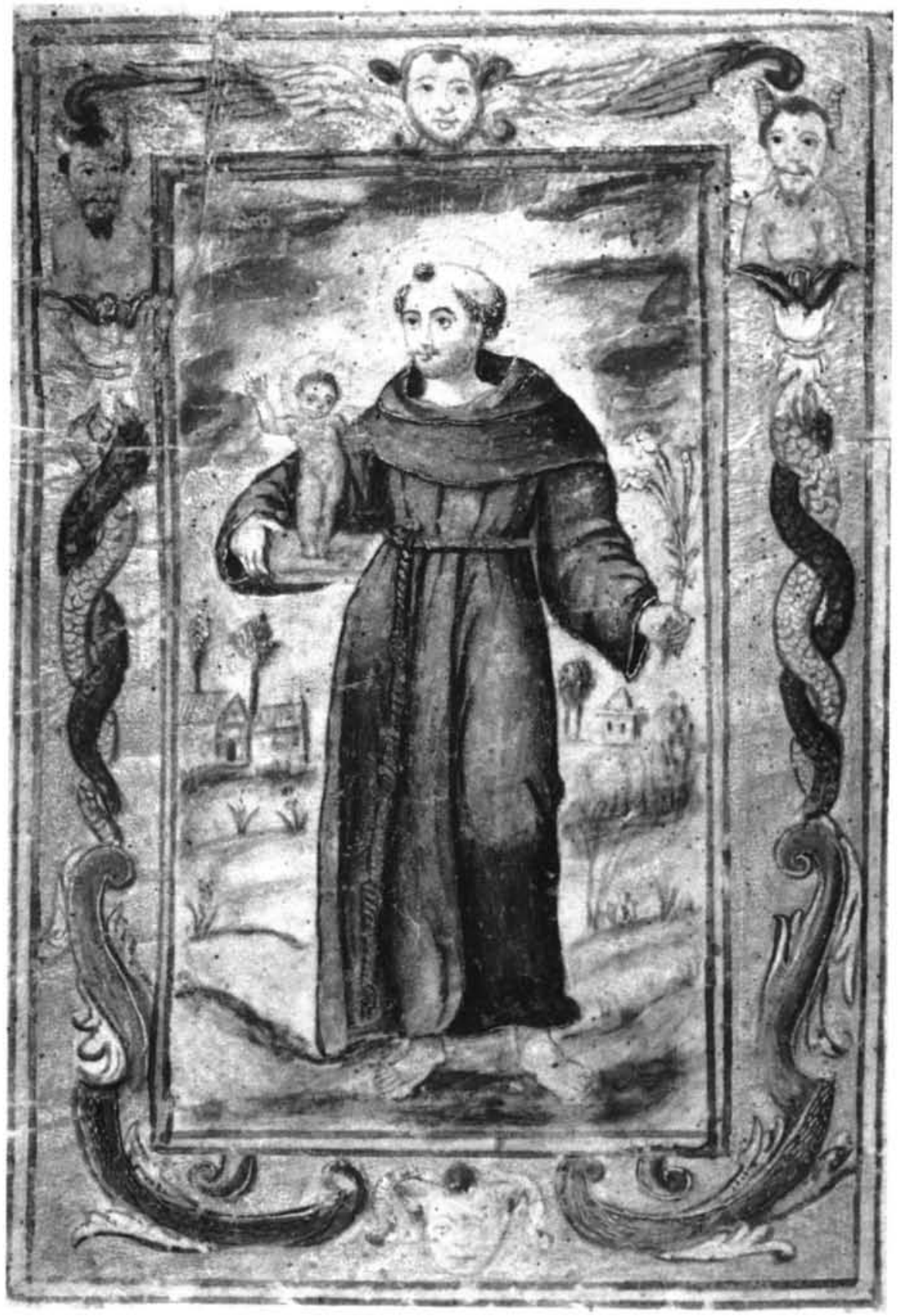

Fig. 3: Libro de Reglas: San Antonio de los Portugueses: Imagen de San Antonio. S. XVII 


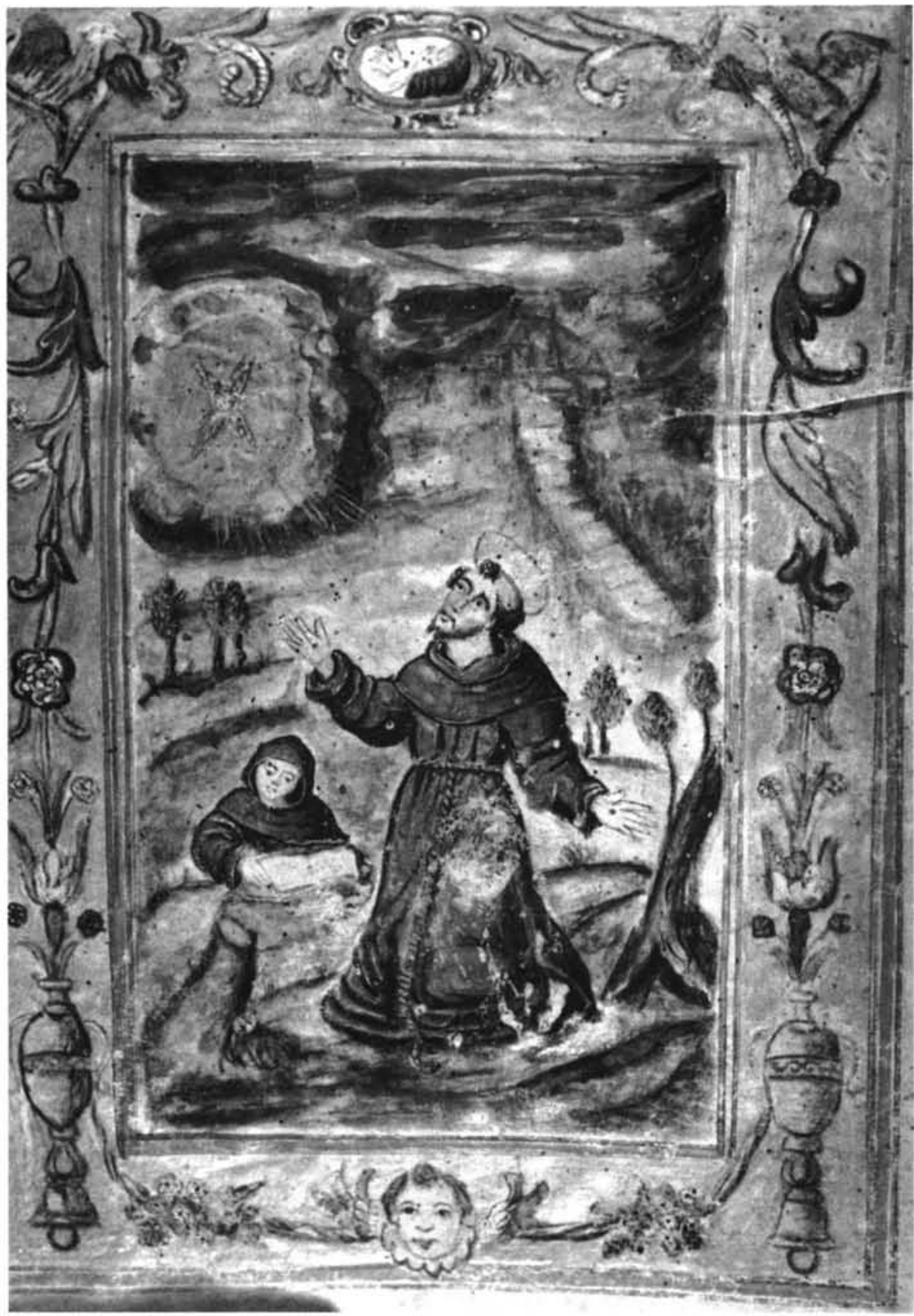

Fig. 4: Libro de Reglas: San Antonio de los Portugueses: Representación de la Estigma de San Francisco. S. XVII. 


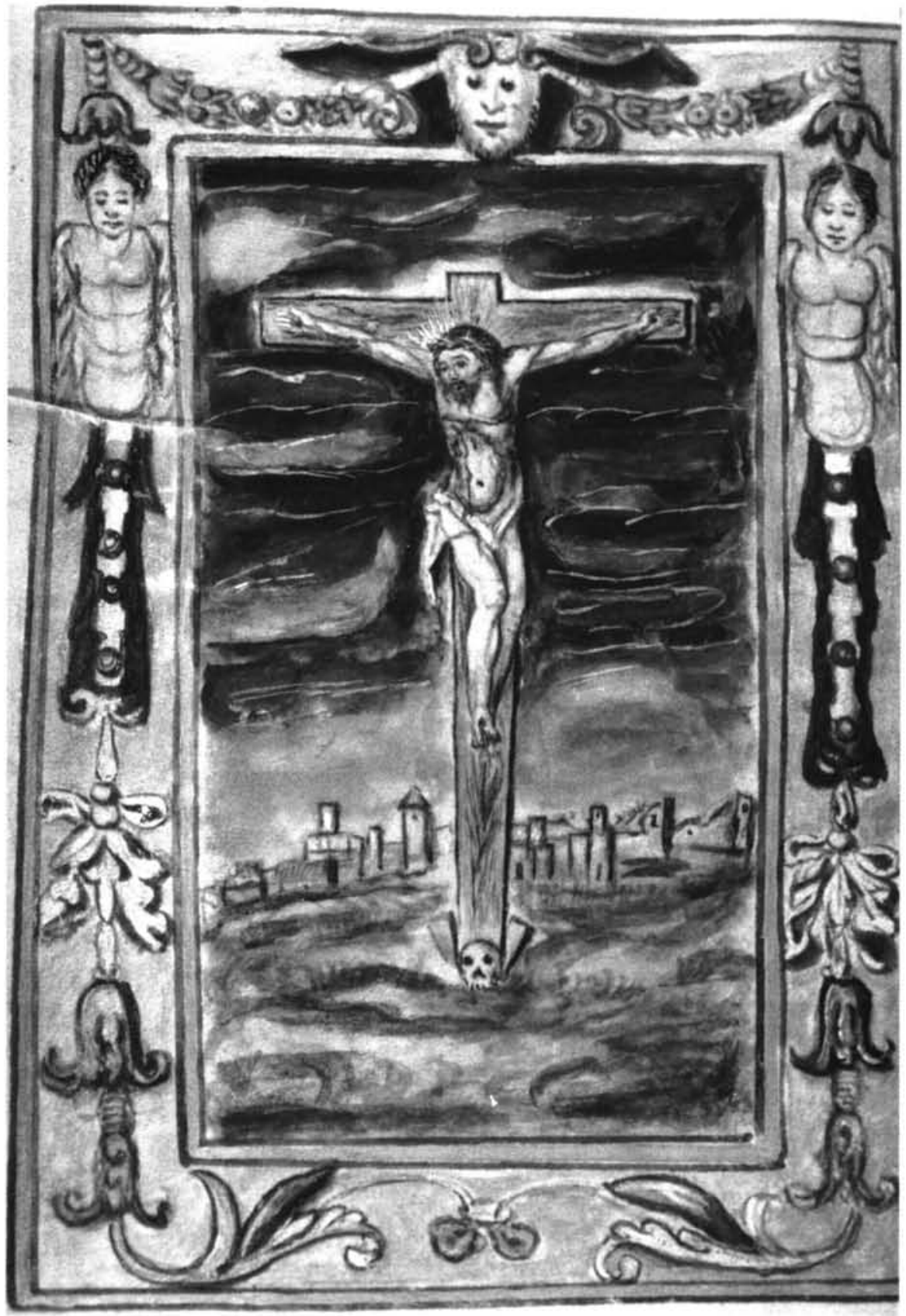

Fig. 5: Libro de Reglas de San Antonio de los Portugueses -Crucificado. S. XVII- 


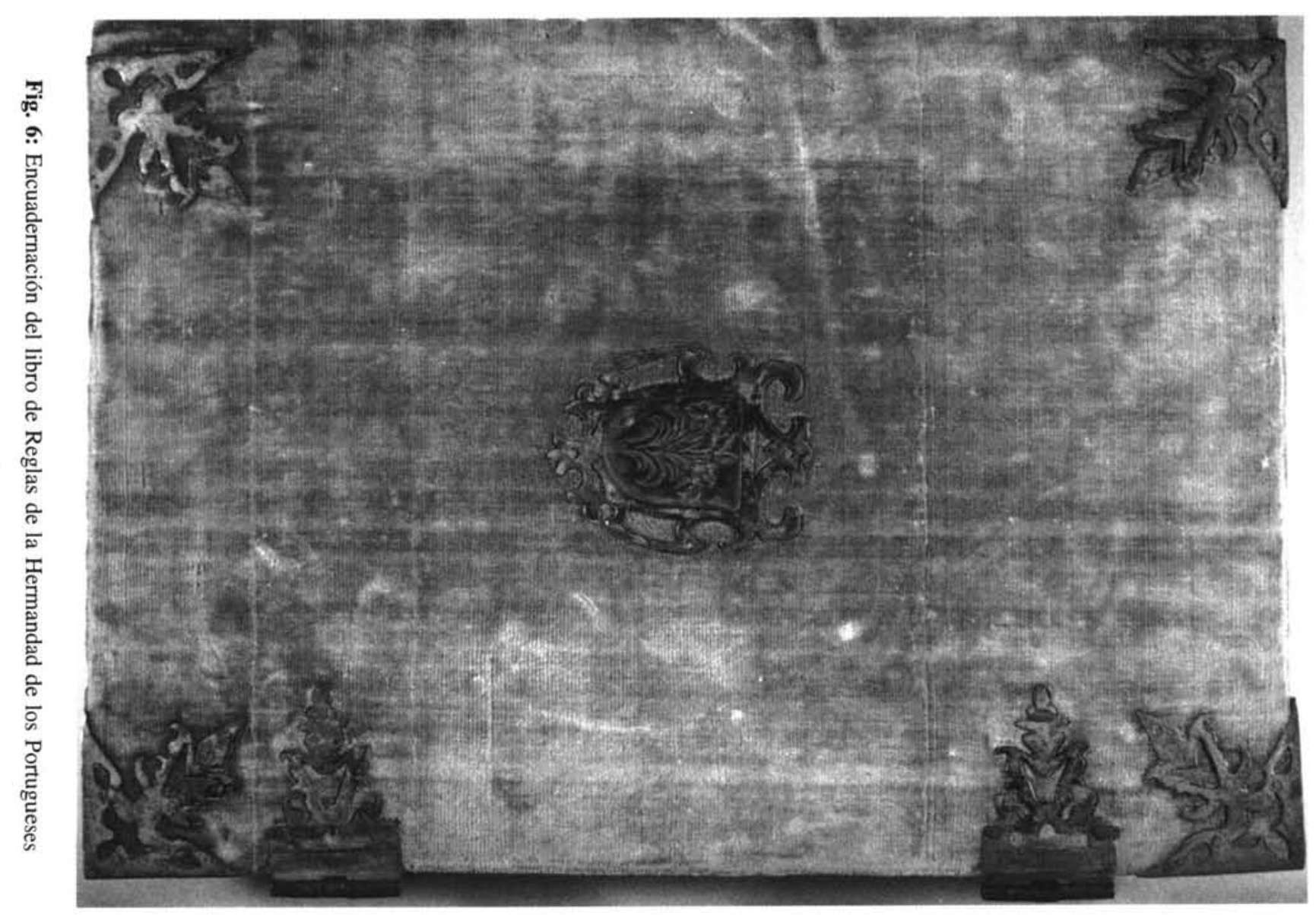



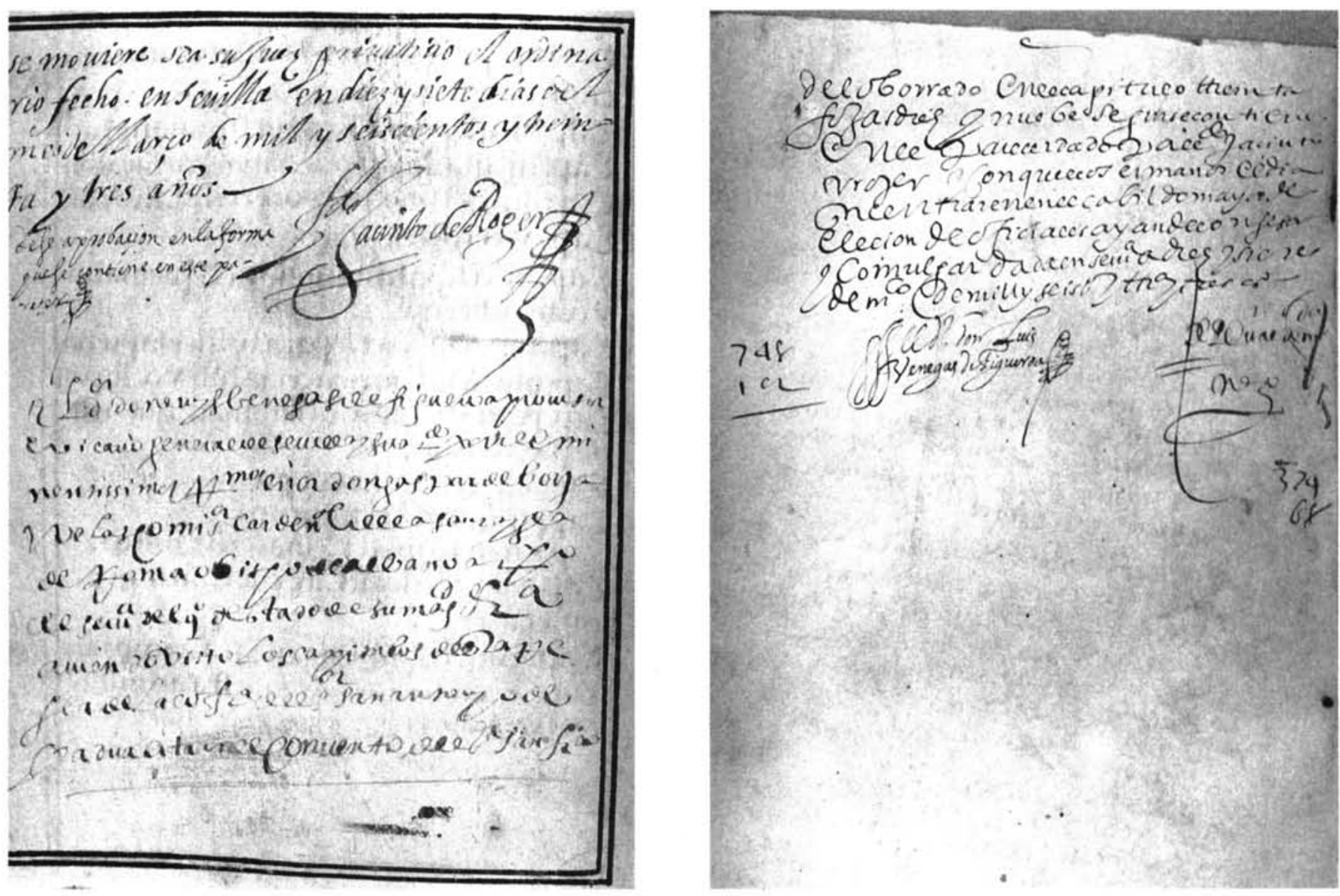

Fig. 7: Testimonio del Traslado y de la Hermandad de los Portugueses: 1733. 